JOURNAL OF ARCHITECUTRE AND URBANISM RESEARCH

Available online http://ojs.uma.ac.id/index.php/jaur

\title{
PERANCANGAN PUSAT KECANTIKAN DAN KESEHATAN DI MEDAN DENGAN TEMA ASITEKTUR BIOKLIMATIK KANNETH YEANG
}

\section{DESIGNING A BEAUTY CENTER IN MEDAN WITH THE THEME OF KANNETH YEANG'S BIOCLIMATIC ARCHITECTURE}

*Islamiyati ${ }^{1)}$, Suprayetno $^{2)}$ \& Yunita Syafitri Rambe ${ }^{3)}$

1) Mahasiswa, Program Studi Arsitektur, Fakultas Teknik, Universitas Medan Area, Indonesia.

2) 3) Dosen, Program Studi Arsitektur, Fakultas Teknik, Universitas Medan Area, Indonesia.

Diterima: Februari 2021; Disetujui: Maret 2021; Dipublikasi: April 2021 *Corresponding author: islamiyati2304@gmail.com

\begin{abstract}
Abstrak
Wanita karir memiliki kesibukan sebagai rutinitas harian karenan pekerjaan dan tuntutan hidup yang lebih tinggi, aktifitas tersebut akan mengakibatkan kelelahan, jenuh juga stress dan berdapmpak buruk pada kesehatan serta kecantikan wanita. Hal tersebut menunjukan pentingnya sebuah pusat kecantikan terlengkap untuk kalangan menengah atas yang mewadahi beberapa fasilitas yaitu pelayanan kesehatan, pelayanan kecantikan dan kelas belajar. Tema bioklimatik memiliki keterkaitan dan tepat untuk diterapkan pada bangunan ini, karena bioklimatik merupakan arsitektur yang berlandaskan pada pendekatan pasif dan minim energi dengan memanfaatkan iklim setempat untuk menciptakan kenyamanan bagi penghuni dan menambah kesan baik untuk wanita yang ingin menghilangkan rasa jenuh dan juga stress. Dalam perancangan ini terdapat beberapa medote yang dilakukan yaitu menentukan ide, mengumpulkan data dan dikelola dengan mengalisis kemudian mendapatkan hasil berupa konsep yang akan digunakan dalam merancang. Luaran dari penelitian ini adalah publikasi pada jurnal nasional.
\end{abstract}

Kata Kunci : Kecantikan, Kesehatan, Arsitektur Bioklimatik, Kanneth Yeang.

\begin{abstract}
Career women have a busy life as a daily routine because of work and higher life demands, these activities will result in fatigue, boredom and stress and have a negative impact on women's health and beauty. This shows the importance of a complete beauty center for the upper middle class that accommodates several facilities, namely health services, beauty services and study classes. The bioclimatic theme is related and appropriate to apply to this building, because bioclimatic is an architecture based on a passive and low energy approach by utilizing the local climate to create comfort for residents and add a good impression for women who want to get rid of boredom and stress. In this design there are several methods that are carried out, namely determining ideas, collecting data and managing it by analyzing and then getting the results in the form of concepts that will be used in designing. The output of this research is publication in a national journal.
\end{abstract}

Keywords: Beauty, Health, Bioclimatic Architecture, Kanneth Yeang. 
How to Cite : Islamiyati, Suprayetno, Yunita S.R (2021). Perancangan Pusat Kecantikan dan Kesehatan di Medan dengan Tema Arsitektur Bioklimatik Kanneth Yeang. JAUR OJournal of Architecture and Urbanism Research). 4 (2): 170-180. 


\section{PENDAHULUAN}

Penduduk Kota Medan yang bekerja dengan jenis kelamin perempuan berumur lima belas tahun ke atas berjumlah 414.521 jiwa pada tahun 2019 menurut data pusat statistik (BPS) Sumatera Utara. Dan menurut pemerintah Kota Medan (PEMKO) belum ada fasilitas lengkap untuk prasarana kecantikan hanya ada 26 unit dibeberapa kecamatan yang memiliki prasarana kecantikan terpisah terkhusus tersedia pusat kesehatan dan kecantikan. Disimpulkan bahwa kurangnya fasilitas di Medan menjadi alasan untuk merancang pusat kecantikan terlengkap agar wanita di medan tidak perlu berpindah tempat untuk dapat menikmati fasilitas yang diinginkan yang berupa kecantikan dan kesehatan.

Target pengunjung pusat kecantikan ini yaitu golongan eksekutif muda yang memiliki ekonomi menegah.

Fungsi pusat kecantikan ini akan di bagi menjadi beberapa jenis pelayanan yaitu, kecantikan, kesehatan dan kelas belajar. Yang terdiri dari perawatan muka, tubuh, bedah plastik serta olahraga tubuh dan terapi kesehatan selain itu ada kelas belajar untuk pelatihan calon dokter.

Untuk pelayanan kecantikan terdapat bebrapa fasilitas yaitu salon, body scrub (lulur), dan bedah plastik. Untuk pelayanan kesehatan terdapat dua fasilitas yang pertama Terapi Kesehatan yaitu akupuntur, aromaterapi, cranial osteopathy, massage, Nutritional Teraphy, dan Reflexology. Yang kedua Kebugaran Tubuh Dengan Olahraga yaitu Terdapat Aerobik, dan yoga.

Adapun pelayanan kelas belajar yaitu kelas yang akan membimbing dan belajar agar menjadi Beuty Teraphist professional serta prosedur pendiri bisnis skincare dan perizinannya. Pembuatan perawatan kecantikan kllinik dan home care product, manajemen skincare profesisional, dan teknik marketing skincare. Pendidikan terlengkap dan modern yang selalu berkembang dan update di dunia kecantikan dengan sertifikat yang terdaftar di Dinas Pendidikan Republik Indonesia yang di akui oleh masyarakat Indonesia dalam dunia pendidikan kecantikan dan akan menjadi satu pioneer di Kota Medan.

Bangunan ini akan diterapkan sesuai dengan tema arsitektur bioklimatik agar pengunjung dapat merasakan kenyamanan yang merupakan karakteristik dari tema tersebut.

Bioklimatik merupakan desain dengan pendekatan arsitektur hijau yang memperhatikan kenyamanan yang berkaitan dengan iklim dan lingkungan tersebut. Pusat kecantikan adalah tempat untuk segala macam aktifitas yang berhubungan dengan kecantikan yang menghasilkan kesejahteraan lahir dan batin dengan pembinaan.

Menurut Dewangga (Megawati \& Akromusyuhada, 2019). Pengertian Arsitektur Bioklimatik yaitu memberikan pandangan untuk dapat menyelesaikan desain dengan memperhatikan lingkungan yang berkaitan dengan iklim dan juga bentuk arsitektur daerah tersebut.

Menurut Yeang (Megawati \& Akromusyuhada, 2019), Arsitektur bioklimatik Adalah ilmumyang mempelajari hubungan antara kehidupan dan iklim pada kesehatan dan aktivitas yang dilakukan sehari-hari.

2018) Arsitektur Yeang (Supriatna dkk., merupakan penyelesaian desain yang memperhatikan dan mempertimbangkan bentuk dan juga lingkungan setempat serta cara untuk memecahkan masalah yang berkaitan dengan iklim dan lingkungannya dan berkaitan dengan penerapan elemenelemen pada bangunan yang dihasilkan oleh 
budaya setempat dan akan berpengaruh pada bangunan yang ditampilkan dari sang arsitektur.

Perekembangan arsitektur menurut (Tumimomor \& Poli, 2011) yaitu berawal dari tahun 1990-an yang merupakan arsitekur modern yang dipengaruhi oleh iklim dan merupakan pencerminan kembali arsitektur Frank Loyd Wright yang terkenal dengan alam dan lingkungan yang merupakan prinsip seni yang tidak hanya mementingkan efisiensinya saja tetapi juga kekuatan, keselarasan, kebijaksanaan bangunannya. Pada tahun 1963 Frank Loyd Wright dan Oskar Niemeyer dan lahirlah Victory Olgay yang memperkenalkan Arsitektur Bioklimatik dan Kenneth yeang menerapkan pada tahun 1990-an pada bangunan tinggi.

Faktor yang mempengaruhi arsitektur bioklimatik menurut pendapat Yeang (dalam Supriatna dkk., 2018) adalah: meminimalkan sumber energi yang tak dapat diperbaharui; menghemat energi dari segi bentuk bangunan, pemilihan material dan penempatan bangunan; mengikuti budaya setempat.

Adapun prinsip Bioklimatik Menurut Yeang (dalam Hasan, 2017) adalah Penempatan Bangunan yang terdiri Oreantasi matahari (pencahayaan) terhadap bangunan yang memanjang sebaiknya menghadap ke utara dan selatan dan bangunan terpendek menghadap ke timur dan barat supaya sedikit menerima radiasi matahari langsung. Yang kedua Oreantasi terhadap Angin (Penghawaan) posisi bangunan dan jendela dapat meningkatkan efek dari ventilasi silang, bukaan jendela dapat membantu udara langsung masuk ketempat yang membutuhkan. Yang kedua
Elemen arsitektur terdapat 4 elemen yaitu yang pertama pelindung matahari, material dan warna, vegetasi, dan unsur air.

Studi Banding Tema ada dua yang pertama The roof-roof House yang Kedua Editt Tower. Dan terdapat dua studi Banding Bangunan sejenis yaitu Viv international Medical Beauty dan Aura Medical Clinic.

\section{METODE PENELITIAN}

Metode perancangan adalah tahapan untuk sebua proses rancangan, metode ini dibutuhkan agar memudahkan perancangan dalam penemuan ide dengan tahapan pengumpulan data, menganalisis dan menghasilkan konsep dari objek rancangan.

Terdapat 4 metode rancangan yang pertama merupakan Ide rancangan yang bermula karena wanita karir meliki kesibukan dan rutinitas karena pekerjaan dan tuntuan hidup dan akan memepengaruhi waktu istirahat yang mengakibatkan stress karena tekanan pekerjaan yang berdampak buruk pada esehatan dan fisik wanita.

Yang kedua yaitu Pengumpulan Data yang terbagi menjadi data primer, sekunder dan studi banding.

Ketiga analisis perancangan yaitu dilakukan terhadap objek untuk menghasilkan pembahasan dan kondisi kawasan perancangan, adapun proses tersebut antara lain ialah analisis tapak, pelaku dan aktifitas, ruang, bangunan struktur dan analisis utilitas yang hasil dari analisis tersebut akan menghasilkan konsep perancangan.

Dan yang terakhir ada Konsep rancangan yang mana merupakan tahap terakhir dari analisis dan menghasilkan konsep yang merupakan penggabungan dari 
beberapa analisis dan juga berdasarkan tema yang akan diterapkan pada bangunan yang akan di rancang, dan terdapat dua konsep yaitu konsep fisik dan konsep non fisiki yang mana konsep fisik merupakan konsep yang berupa bentuk dasar bangunan, konsep penerapan bioklimatik, struktur, dan konsep utilitas. Sedangkan konsep non fisik merupakan konsep yang berupa deskripsi tapak, klimatologi yang berupa matahari, angina, kebisingan, oreantasi bangunan, sirkulasi, parkiran dan konsep vegetasi.

\section{PEMBAHASAN}

Lokasi Pusat Kecantikan berada di Jalan .Putri Hijau Kecamatan Medan Barat, Kota Medan, Sumatera Utara, 20371, dan merupakan sarana peruntukan untuk pusat pelayanan dan bisnis. Luas lahan :

$20.000 \mathrm{~m}^{2}$, KDB ( Koifisien Dasar Bangunan) : 60\%, KLB ( Koifisien Lantair Bangunan) : $3, \mathrm{KDB}=$ Luas Lahan $\mathrm{x} \mathrm{KDB}$ $=20.000 \times 60 \%=12.000 \mathrm{~m}^{2} \mathrm{KLB}=$ Luas Lahan $\mathrm{x}$ KLB (Luas Maksimal) $=20.000 \mathrm{x}$ $3=60.000 \mathrm{~m}^{2}$

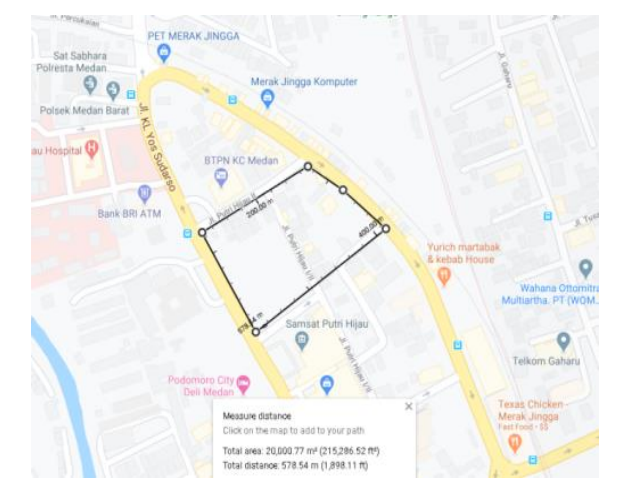

Gambar 1. Lokasi Tapak

(Sumber : https://www.google.com/maps)

Main entrance berada di jalan putri hijau yang merupakan jalan utama dilalui beberapa kendaraan dan merupakan akses masuk bagi pengunjung baik roda dua maupun roda empat serta pejalanan kaki, side entrance berada di Jalan Putri hijau III yang merupakan akses untuk pada pengelola masuk dan keluar bangunanan.

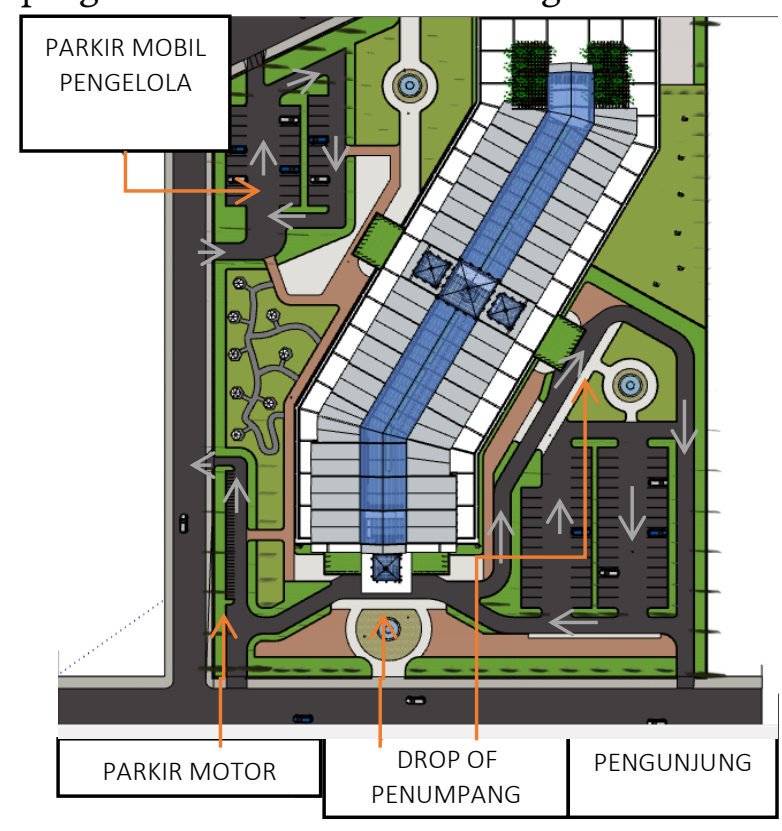

Gambar 2. Sirkulasi dalam bangunan

(Sumber : Analisis Pribadi, 2020)

Posisi parkiran ditempatkan di area selatan bangunan karena area ini merupakan view dari sudut pandang sempit maka bangunan tidak akan terlihat dengan jelas maka dijadikan area parkiran. Dan menggunakan pola parkir yang membentuk sudut $90^{\circ}$ untuk kendaraan roda dua dan roda empat.

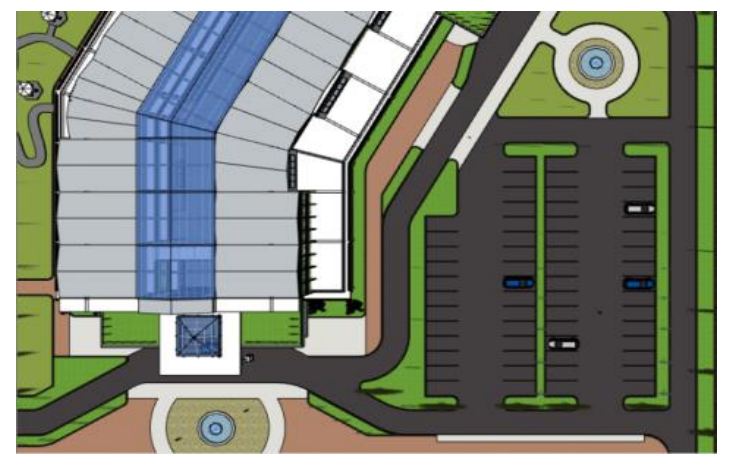

Gambar 3. Parkiran 90 은

(Sumber Analisis Pribadi, 2020)

Pada zona publik ditempatkan didekat main entrance karena bersifat umum dan memiliki tingkat keramaian yang tinggi zona public diletakkan ruang seperti ruang lobby. zona private terletak pada tapak yang 
tingkat keramaian nya rendah karena zona ini digunakan sebagai area private seperti ruang operasi. Zona semi private terletak didalam tapak karena zona ini tidak berhubungan langsung dengan akses masuk. zona service ditepatkan di arean belakang karena jauh dari pengunjung dan meiliki jalur tersendiri.

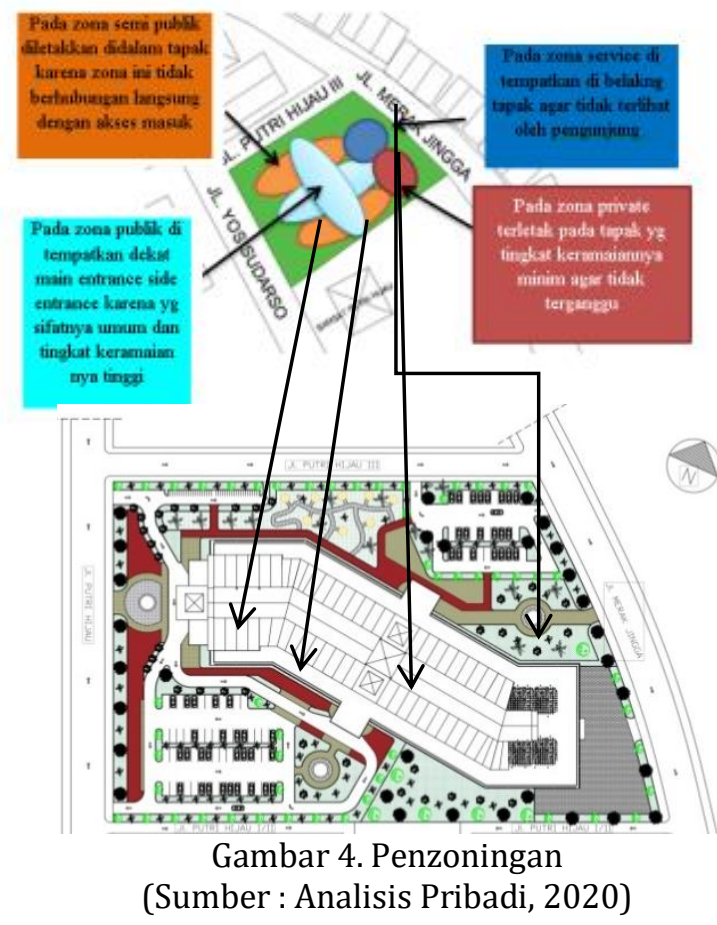

Pengunjung dari pusat kecantikan ini terdiri dari beberapa pengendara, ada pengendara sepada motor, mobil dan pejalan kaki yang menggunakan angkutan umum. Setelah sampai bagi pengendara mobil maupun sepeda motor setelah masuk langsung parkir lalu langsung ke lobby lalu konsultasi dan bisa langsung ketempat ke ruangan lalu pulang. Secara besar urutan nya yaitu :

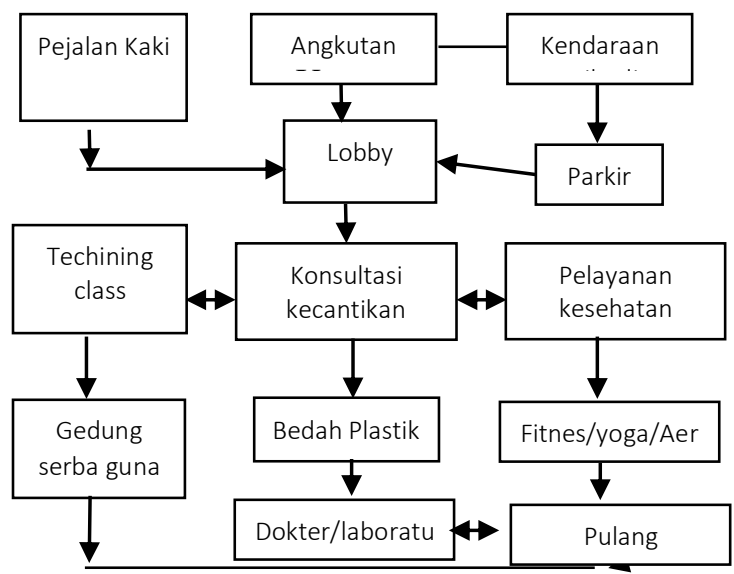

Skema 1. Analisis sirkulasi Pengunjung

(Sumber : Analisis Pribadi, 2020)

Pengelola merupakan orang yang bekerja dan ikut mengembangkan Pusat Kecantikan ini seperti pemimpin/ penanggung jawab bangunan ini dan karyawannya, para dokter dan suster yang memberikan pengobatan serta menangung beban citra baik bangunan ini. Secara besar urutannya yaitu :

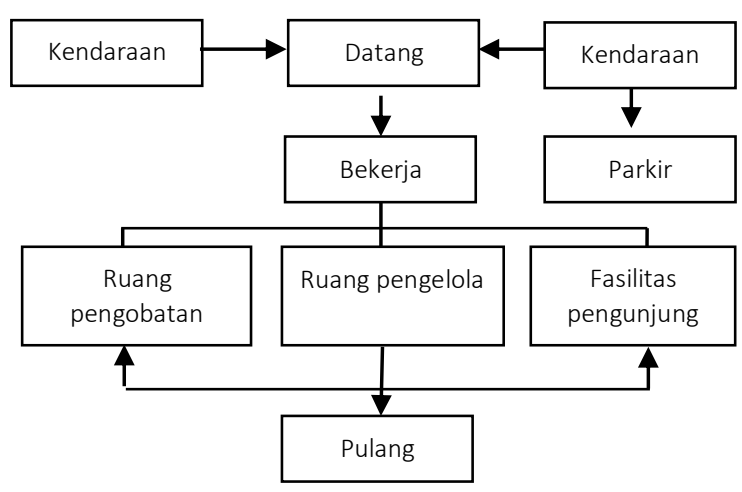

Skema 2. Analisis Sirkulasi Pengelola

(Sumber : Analisis Pribadi, 2020)

Menggunakan bentuk persegi dan persegi panjang kemudian bentuk tersebut digabungkan dan bentuk bertranformasi persegi di gunakan untuk area lobby, persegi panjang dijadikan sikulasi utama dan linier serta adanya atrium dan persegi terakhir digunakan sebagai area layanan. Bentuk 
persegi panjang berputar $30^{\circ}$ dan menjadikan bangunan memanjang menghadap selatan dan utara dan merupakan penerapan dari arsitektur bioklimatik karena radiasi matahari lebih sedikit masuk kedalam bangunan.

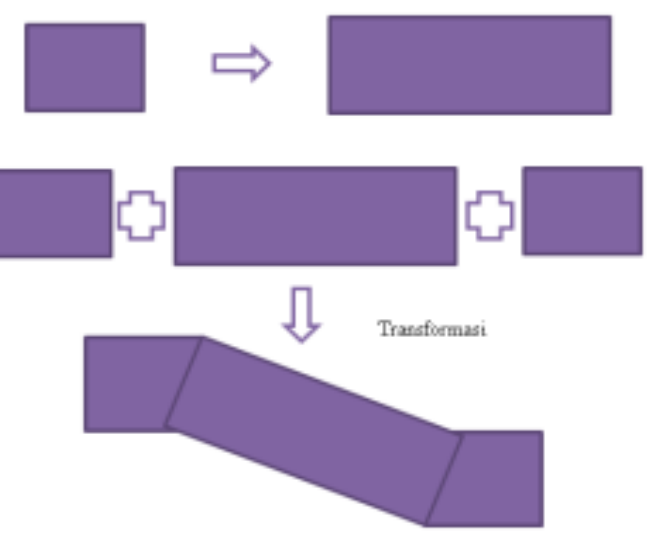

Gambar 5. Konsep Bentuk Dasar Bangunan

(Sumber : Analisis Pribadi, 2020)

Penerapan Bioklimatik pada bangunan ini terdapat dibeberapa titik yaitu

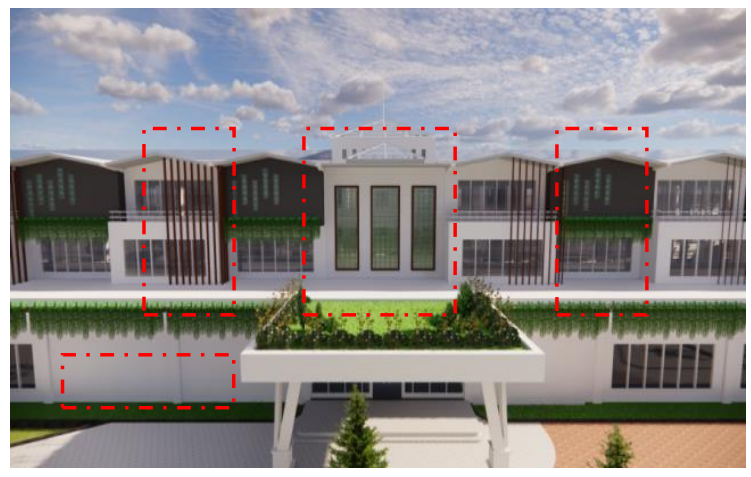

Gambar 6. Penerapan Arsitektur Bioklimatik

(Sumber : Analisis Pribadi, 2020)

Warna material juga berpengaruh terhadap serapan, warna muda memiliki serapan kalor yang lebih sedikit dan kecil dari warna tua. warna putih memiliki angka serapan kalor paling sedikit yaitu (10-15\%). Sebaliknya warna hitam dengan permukaan tekstur kasar dapat menyerap kalor sampai $95 \%$.

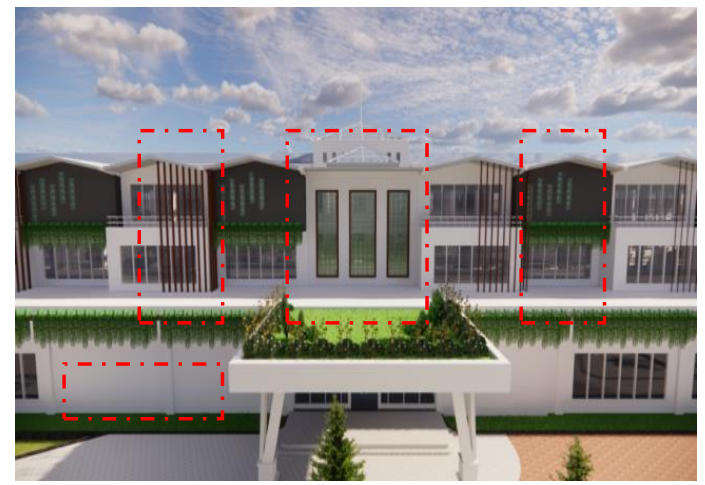

Gambar 7. Penerapan Arsitektur Bioklimatik (Sumber : Analisis Pribadi, 2020)

Pelindung Matahari memberikan pelindungan terhadap sinar matahari yaitu berupa vertical louver Screen. dan memberikan ventilasi dapat meningkatkan efek ventilasi silang didalam ruang.

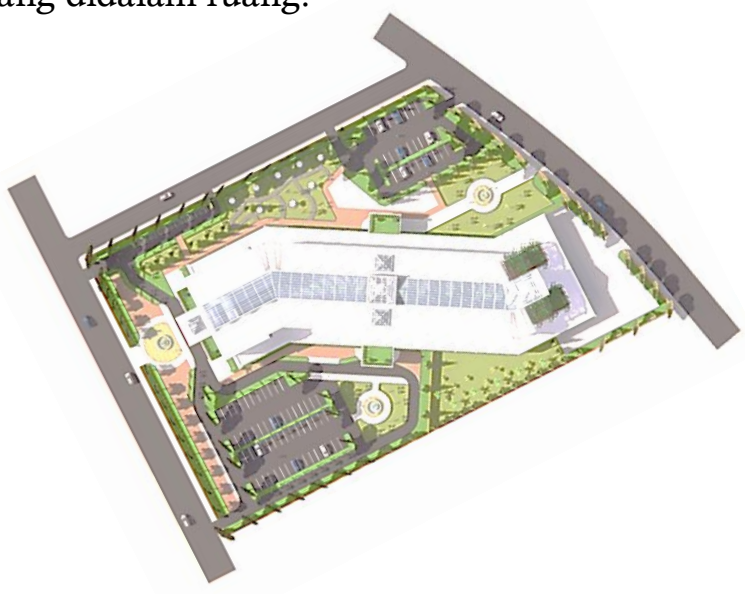

Gambar 8. Penerapan Arsitektur Bioklimatik

(Sumber: Analisis Pribadi, 2020)

Keberadaan pohon akan menurunkan suhu udara dan radiasi matahari akan terserap oleh daun dan unsur efektif dalam menghalau cahaya matahari, adanya atrium sebagai pencahayaan alamai dengan material tinted glass, oreantasi terhadap matahari, Bagian memanjang menghadap utara-selatan. 
Adapun detail Bioklimatik yang terdapat pada bangunan ini yaitu :

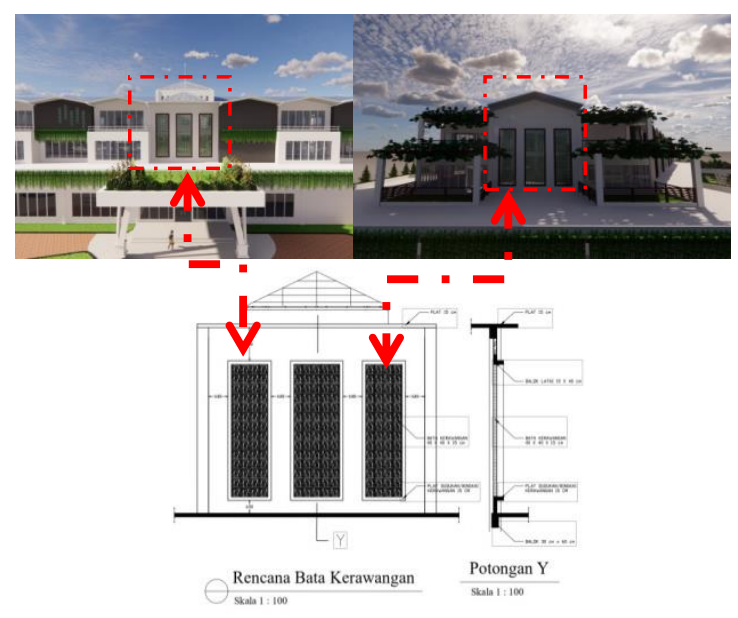

Gambar 9. Detail Rencana Bata Kerawangan

(Sumber : Analisis Pribadi, 2020)

Meminimalkan ketergantungan pada sumber energi yang tak dapat diperbaharui dan Pemberian ventilasi yang cukup pada ruangan berupa kerawangan yang berfungsi mengalirkan udara dari luar kedalam dan udara panas di dalam gedung dapat dialirkan kelingkungan luar sehingga dapat menyegarkan ruangan.

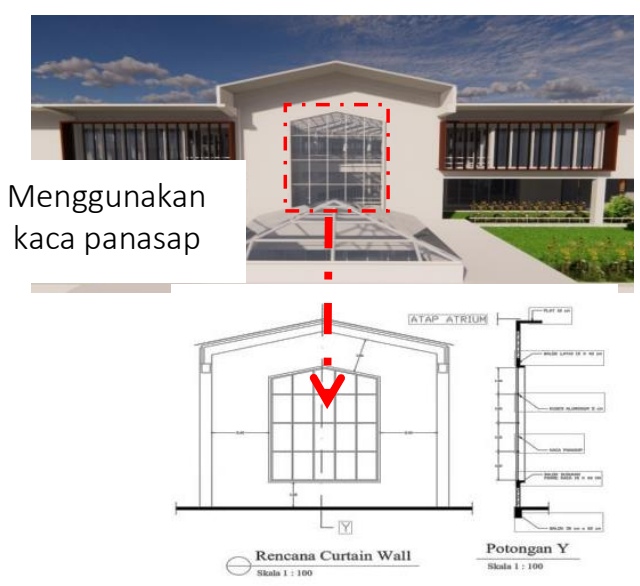

Gambar 10. Detail Rencana Curtain Wall

(Sumber: Analisis Pribadi, 2020)
Mengurangi konsumsi energi dengan memanfaatkan unsur alam yaitu pencahayaan alami yang masuk kedalam bangunan dan sinar matahari hasil pemantulan cahaya dari benda - benda yang terdiri dari di luar banguna dan masuk ke dalam ruangan melalui bukaan yang berfungsi sebagai pencahaya alami pada bangunan.
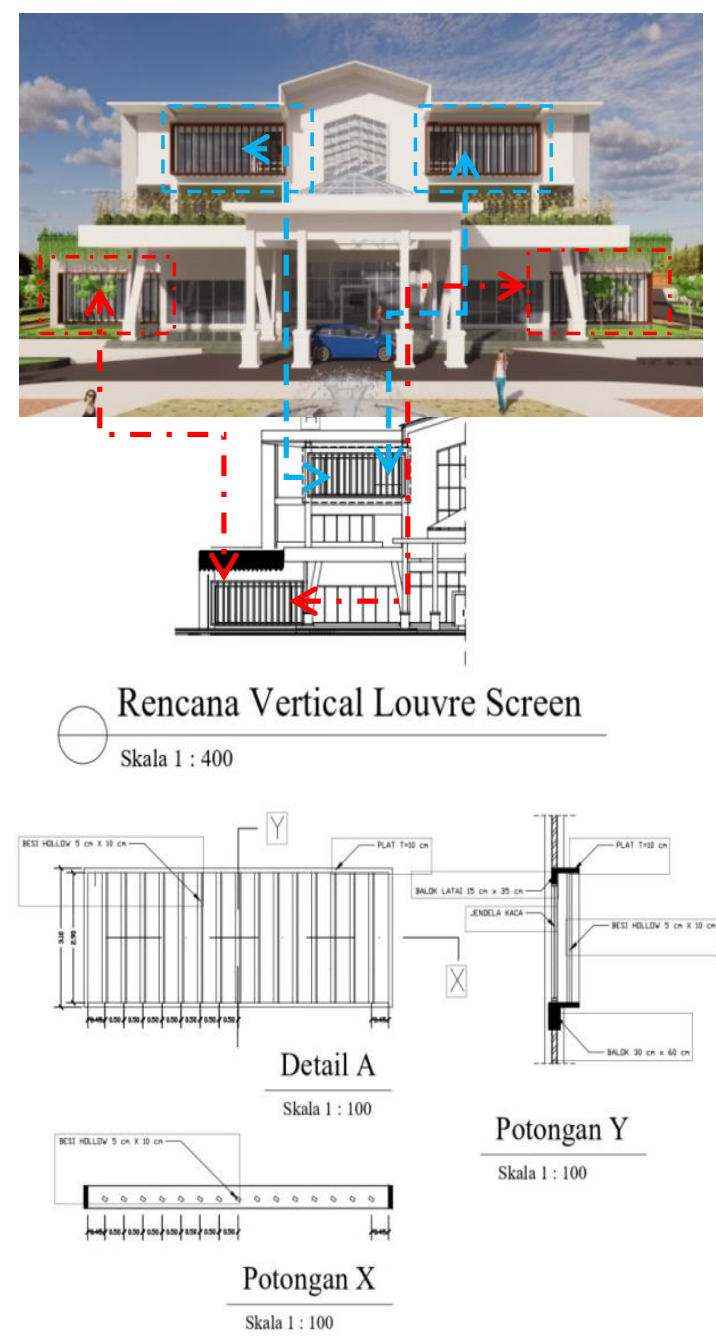

Gambar 11. Detail Vertikal Louver Screen (Sumber : Analisis Pribadi, 2020)

Karena fasad menghadap ke barat dan terkena matahari sore maka pandangan melalui jendela pada sisi ini harus dihindari 
dengan menggunakan elemen pelindung matahari berupa vertical Louvre Screen, pembayang akibat sinar matahari adalah esensi pembiasan sinar matahari pada dinding yang menghadap secara langsung (pada daerah tropis berada di sisi timur dan barat) dan berfungsi sebagai pembayangan untuk menhindari sinar matahari.
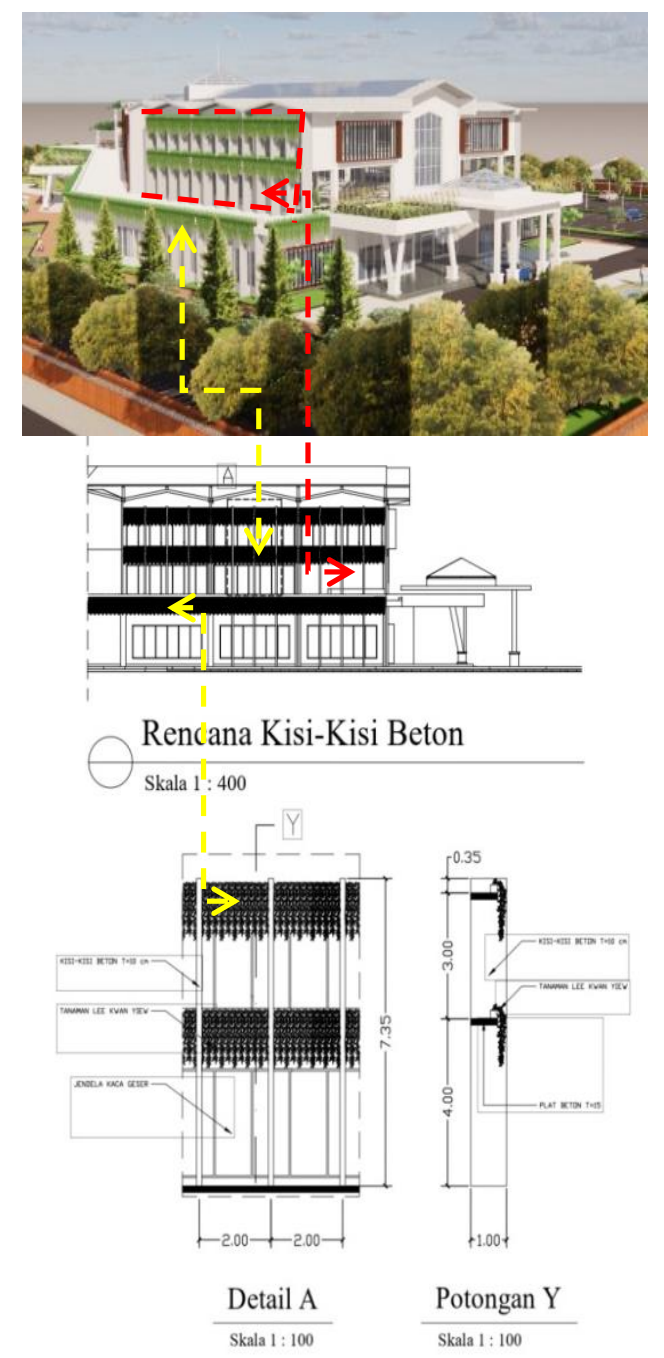

Gambar 12. Detail Kisi-kisi Dan Vegetasi

(Sumber : Analisis Pribadi, 2020)

Karena pasad menghadap ke barat dan terkena matahari sore maka pandangan melalui jendela pada sisi ini harus dihindari dengan menggunakan elemen pelindung matahari berupa kisi-kisi beton, tanaman pada bangunan ini juga berfungsi sebagai penghalang sinar masuk kedalam bangunan sekaligus dapat mebuat bangunan menjadi sejuk, tanaman rambat juga dapat mempercantik eksetrior pada bangunan pusat kecantikan ini.

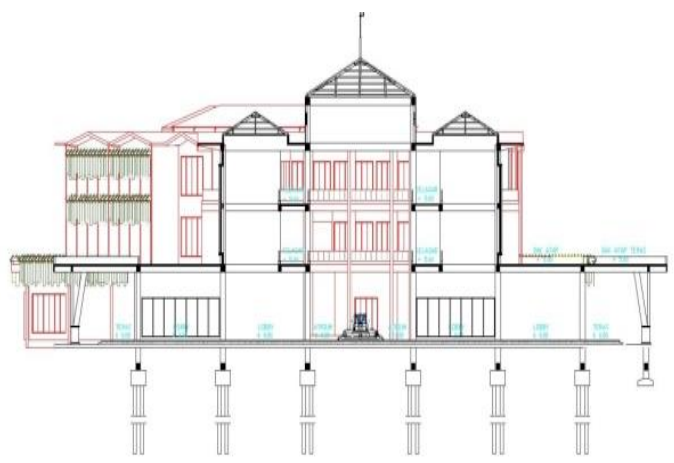

Gambar 13. Struktur

(Sumber : Analisis Pribadi, 2020)

Struktur atas atau bagian atap menggunakan atap plat beton dan beton penompang atap kaca, struktur tengah menggunakan kolom dan balok beton bertulang, sedangkan struktur bawah menggunakan pondasi bored pile.

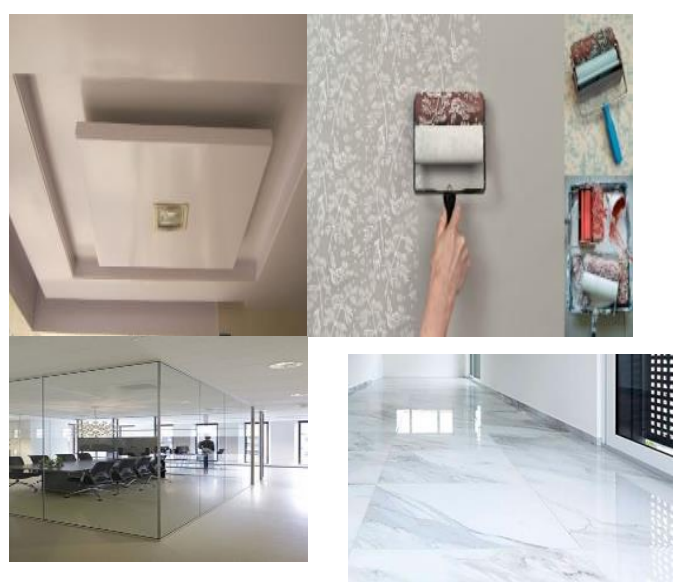

Gambar 14. Material Pada Bangunan

(Sumber : Analisis Pribadi, 2020)

Plafon menggunakan bahan gypsum karena dapat menyerap suara dan juga terlihat lebih rapi dan bersih, selain itu penggunaan wallpaper pada dinding juga untuk mempercantik ruangan sekaligus untuk melndungi dinding dan dibeberapa ruangan, dan dibeberapa pusat kebugaran, 
ruang fitness menggunkan kaca dikeliling dinding dan juga cermin yang bertujuan untuk mengamati dan melihat gerakan sendiri saat latihan.Lantai pada ruangan menggunakan material marmer karena lebih tahan lama dan juga berkesan mewah.

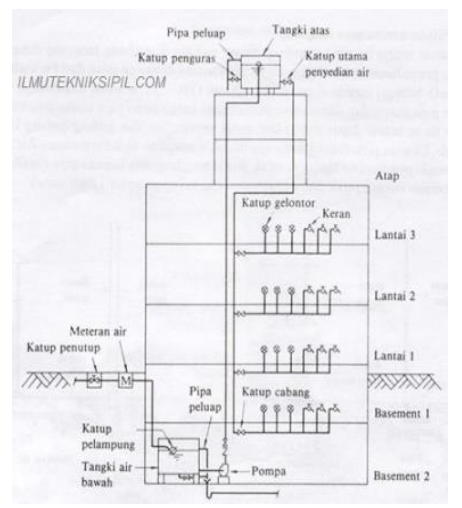

Gambar 15. Sistem Utilitas Plumbing (Sumber : Analisis Pribadi, 2020)

Air berasal dari PDAM dan juga sumur, air akan dipompa ke atas kemudian ditampung pada tangkai air, dari toren air diturunkan lagi kebawah melalui pipa-pipa yang berada pada shaft, system ini memanfaatkan grafitasi, sistem ini juga sangat hemat terhadap penggunaan energi listrik.

Sistem Pembuangan Air Kotor

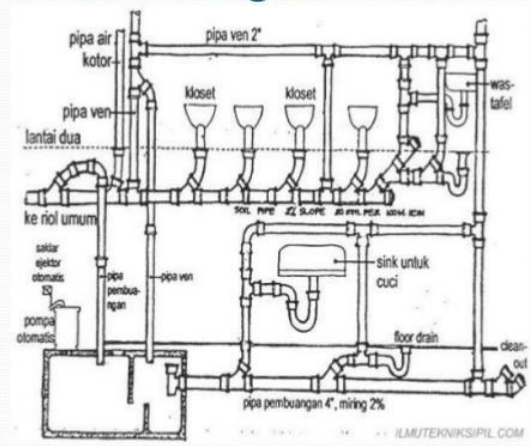

Gambar 16. Sistem Utilitas Plumbing Air kotor (Sumber : Analisis Pribadi, 2020)
Sistem air kotor padat dari closet di alirkan ke septitank kemudian disalurkan ke sewage treatmen dan diolah hingga aman lalu dialirkan ke roil kota.

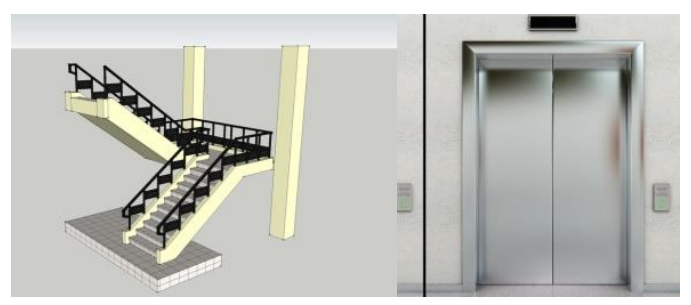

Gambar 17. Sistem Pengankutan Vertikal

(Sumber : Analisis Pribadi, 2020)

Pada bangunan ini menggunakan sistem pengangkutan vertikal berupa lift yang merupakan akses utama dan juga terdapat tangga darurat di bangunan tersebut.

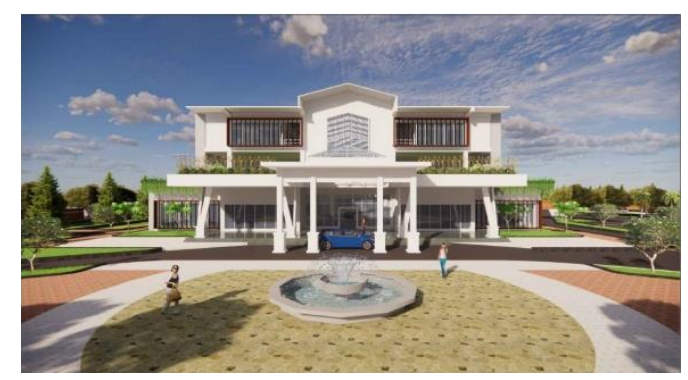

Gambar 18. Tampak Belakang (Sumber : Analisis Pribadi, 2020)

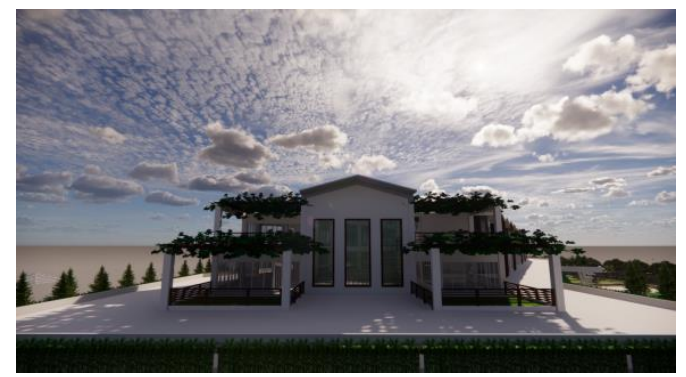

Gambar 19. Tampak Belakang (Sumber : Analisis Pribadi, 2020) 


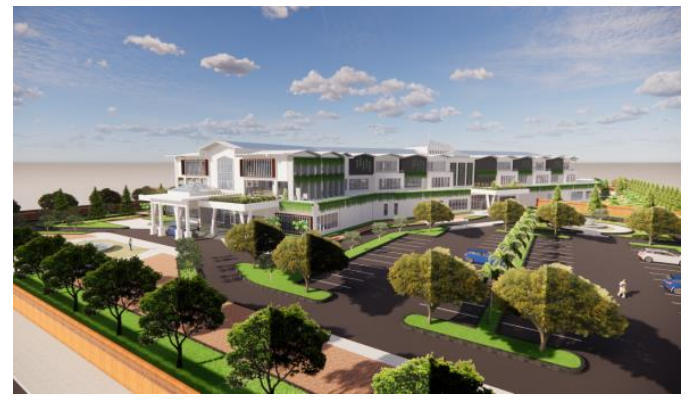

Gambar 20. Tampak Kanan (Sumber : Analisis Pribadi, 2020)

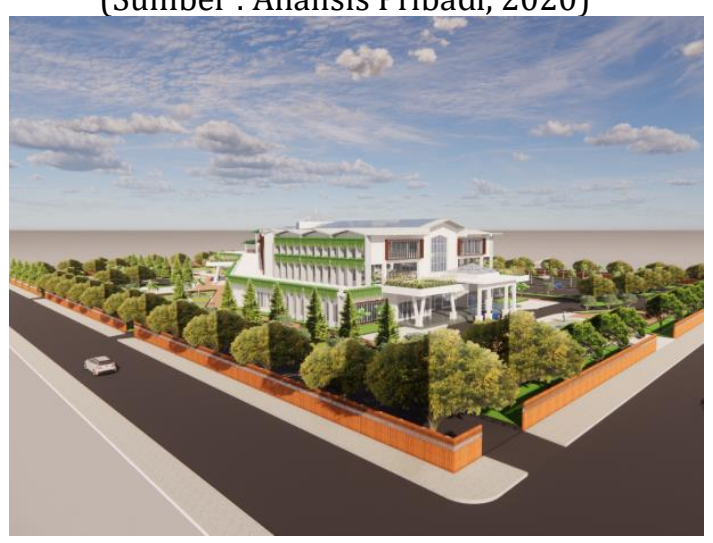

Gambar 21. Tampak Kiri (Sumber : Analisis Pribadi, 2020)

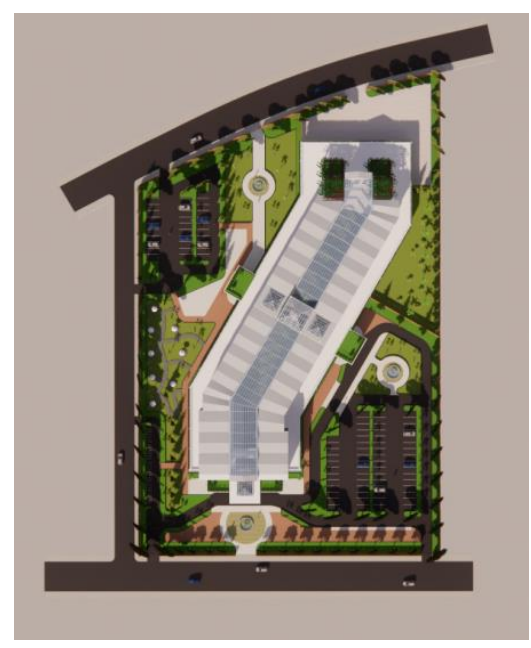

Gambar 22. Tampak Atas

(Sumber : Analisis Pribdi, 2020)

\section{SIMPULAN}

Dari proses pengumpulan data, kemudian analisis yang menghasilkan konsep rancangan, dan dilakukan evaluasi terhadap hasil rancangan, terdapat beberapa poin yang disimpulkan bahwa:
Memaksimalkan fasade ke arah timur dan barat karena arah tersebut mengarah langsung ke jalan utama yang sangat memungkinkan bangunan terlihat, bangunan sebaiknya di maksimalkan menghadap selatan dan utara agar tidak menerima radiasi matahari berlebihan, serta menambahkan atrium dengan kaca yang mampu mengurangi panas, agar banguna dapat menerima cahaya dari segala sisi sesuai dengan karakteristik arsitektur bioklimatik, Struktur atas atau bagian atap menggunakan Atap Plat beton dan beton penopang atap kaca. Struktur tengah menggunkana kolom dan balok beton bertulang. Struktur bawah atau pondasi menggunakan pondasi bored pile.

\section{DAFTAR PUSTAKA}

Hasan, W. (2017). Perencanaan Gedung Neurologi dengan Pendekatan Arsitektur Bioklimatik. Skripsi. Universitas Islam Negri Alauddin.

Chiara, D. J., Callender, J. H. (1983). Time-Saver Standard For Building Types 2nd Edition. U.S.A. Mc Graw Hill.

Ching, F. D. K., (2015). Architecture Form, Space, \& Order Fourth edition. New Jersey: John Wiley \& Sons, Inc.

Megawati, L. A., \& Akromusyuhada, A. (2019). \begin{tabular}{lcr} 
PENDEKATAN & \multicolumn{2}{r}{ ARSITEKTUR } \\
BIOKLIMATIK & PADA & KONSEP \\
BANGUNAN & SEKOLAH & HEMAT
\end{tabular} ENERGY. Arsitektura, 17(1), 77-86. https://doi.org/https://dx.doi.org/10.20961/ arst.v17i1.24376

Nuefert, Ernst. (1996). Data Arsitek Jilid I Edisi 33. Terjemahan oleh Sunarto Tjahjadi. Jakarta: Erlangga.

Neufert, Ernst. (1996). Data Arsitek Jilid 2 Edisi 33. Terjemahan oleh Sunarto Tjahjadi. Jakarta. Erlangga.

Supriatna, Laksmitasari, R., \& Arum, R. (2018). Perancangan Kantor Sewa dengan Pendekatan Arsitektur Bioklimatik. Jurnal Desain, 5(01), $44-52$.

https://doi.org/10.30998/jurnaldesain.v5i01. 2178

Tumimomor, I. A. G., \& Poli, H. (2011). Arsitektur Bioklimatik. Media Matrasain, 8(1), 104-117. https://jurnal.uns.ac.id/Arsitektura 